\title{
An Assessment of External Price Competitiveness for Mozambique
}

\author{
Francis Vitek
}




\title{
IMF Working Paper
}

SPR

An Assessment of External Price Competitiveness for Mozambique

Prepared by Francis Vitek*

Authorized for distribution by Martin Mühleisen

August 2009

\begin{abstract}
This paper conducts an assessment of external price competitiveness for Mozambique. A variety of indicators suggest that Mozambique has recently lost external price competitiveness with respect to its major trading partners. Consistent with these indicators, an exchange rate assessment indicates that the metical is overvalued by 26 to 41 percent in real effective terms. If sustained, an overvaluation of this magnitude has the potential to retard economic growth and jeopardize external stability, calling for an adjustment of monetary policy to gradually restore external price competitiveness.
\end{abstract}

\section{This Working Paper should not be reported as representing the views of the IMF.}

The views expressed in this Working Paper are those of the author(s) and do not necessarily represent those of the IMF or IMF policy. Working Papers describe research in progress by the author(s) and are published to elicit comments and to further debate.

JEL Classification Numbers:F31; F32

Keywords: External price competitiveness; exchange rate assessment; macroeconomic balance approach; equilibrium real exchange rate approach; external sustainability approach

\section{Author's E-Mail Address: Fvitek@imf.org}

*The author gratefully acknowledges advice provided by Robert Sharer and Nicholas Staines, in addition to comments and suggestions received from seminar participants at the Ministry of Finance of Mozambique. 


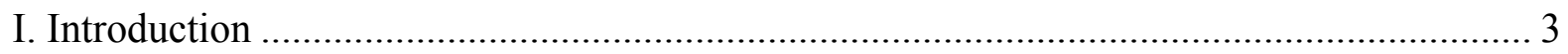

II. Indicators of External Price Competitiveness ......................................................... 3

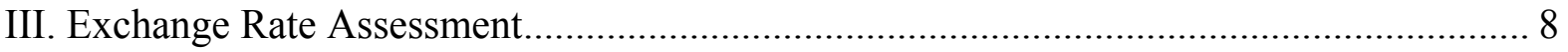

A. The Macroeconomic Balance Approach.................................................................. 9

B. The Equilibrium Real Exchange Rate Approach ............................................... 12

C. The External Sustainability Approach ................................................................... 14

D. Summary of Exchange Rate Assessment Results .................................................. 16

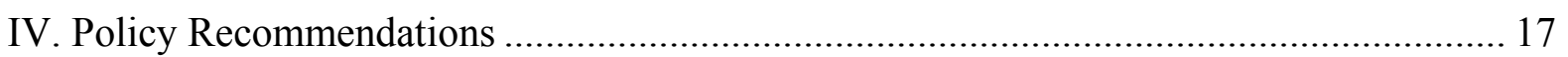

Tables

1. Estimation Results for the Macroeconomic Balance Approach ..................................... 11

2. Estimation Results for the Equilibrium Real Exchange Rate Approach ......................... 13

3. Estimation Results for the External Sustainability Approach....................................... 15

4. Summary of Exchange Rate Assessment Results......................................................... 17

Figures

1. Real Effective Exchange Rate versus Nominal Effective Exchange Rate ....................... 4

2. Nominal Effective Exchange Rate versus Nominal Bilateral Exchange Rates .................. 5

3. Real Effective Exchange Rate versus Real Bilateral Exchange Rates ............................ 6

4. Real Effective Exchange Rate versus Terms of Trade ............................................ 7

5. Real Effective Exchange Rate versus Trade and Current Account Balances ..................... 8

6. Real Effective Exchange Rate versus Estimated Long Run Equilibrium Value ................ 9

7. Current Account Balance versus Estimated Medium Run Equilibrium Value.................. 12

8. Real Effective Exchange Rate versus Estimated Medium Run Equilibrium Value ........... 14

9. Net Foreign Asset Position versus Estimated Medium Run Equilibrium Value............... 16

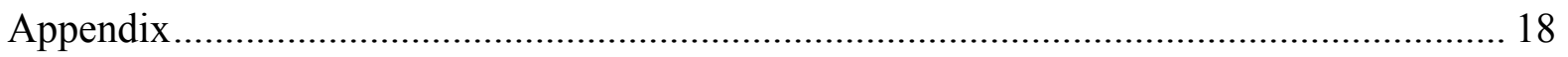

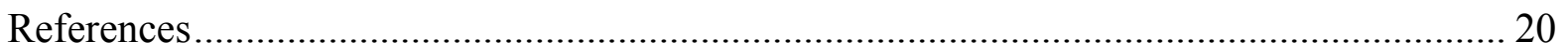




\section{INTRODUCTION}

The metical has appreciated substantially in nominal and real effective terms during recent months. This real appreciation may have reduced the external price competitiveness of Mozambique, and has potential implications for its economic development.

This paper conducts an assessment of external price competitiveness for Mozambique, and considers its policy implications. In addition to examining a variety of indicators of external price competitiveness, it implements an exchange rate assessment based on the macroeconomic balance, equilibrium real exchange rate, and external sustainability approaches discussed in Lee et al (2008). In order to accommodate the case of Mozambique, these analytical approaches, which were designed to apply to advanced and emerging economies, are extended to apply to developing economies.

A variety of indicators suggest that Mozambique has recently lost external price competitiveness with respect to its major trading partners. Consistent with these indicators, an exchange rate assessment indicates that the metical is overvalued by 26 to 41 percent in real effective terms. If sustained, an overvaluation of this magnitude has the potential to retard economic growth and jeopardize external stability, calling for an adjustment of monetary policy to gradually restore external price competitiveness.

External price competitiveness is only one aspect of external competitiveness, which also encompasses structural characteristics of the economy. The traditional export base of Mozambique, which excludes megaprojects, is small and poorly diversified. Traditional exports are concentrated in a few agricultural products - tobacco, sugar, cotton, prawns and cashews - whose production is weather sensitive and subject to terms of trade shocks. In addition to increasing external price competitiveness, stimulating growth in the traditional export sector requires raising labor market flexibility and reducing transportation costs.

The organization of this paper is as follows. The next section examines a variety of indicators of external price competitiveness. An exchange rate assessment based on the macroeconomic balance, equilibrium real exchange rate, and external sustainability approaches is conducted in section three. Finally, section four offers policy recommendations.

\section{Indicators of External Price Competitiveness}

There are a variety of alternative indicators of external price competitiveness. Principal among these are the real effective exchange rate, which measures the price of domestic goods and services in terms of foreign goods and services, and the terms of trade, which measures the price of exports in terms of imports.

The metical has appreciated substantially in real effective terms during recent months. This loss of external price competitiveness was driven almost entirely by nominal effective appreciation. The real effective exchange rate for Mozambique is plotted versus the nominal 
effective exchange rate in Figure 1. Divergences of the real effective exchange rate from the nominal effective exchange rate reflect accumulated inflation rate differentials relative to trading partners. In real effective terms, the metical appreciated by 24 percent during the year through March of 2009. In nominal effective terms, it appreciated by 23 percent over this period.

Figure 1. Real Effective Exchange Rate versus Nominal Effective Exchange Rate

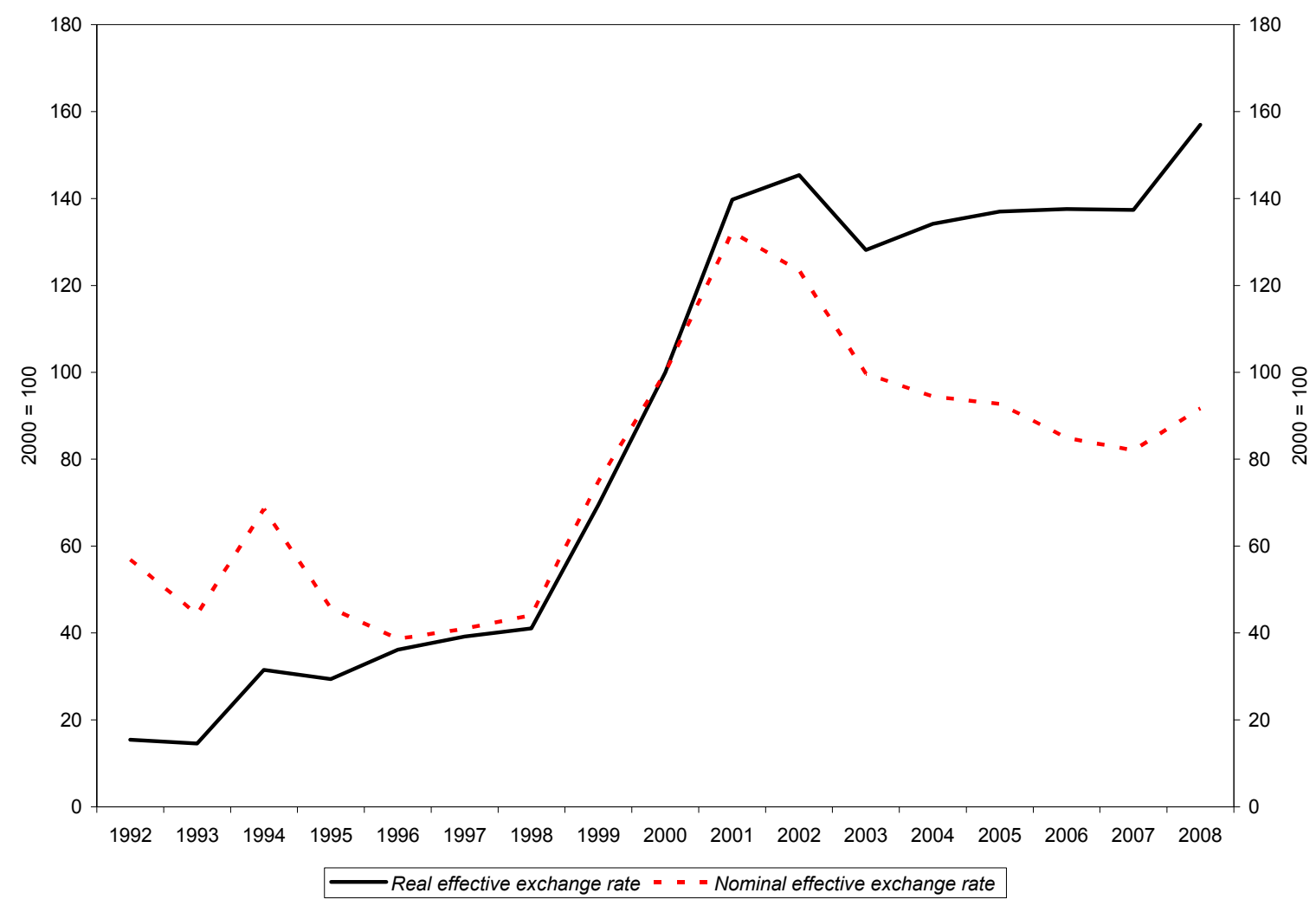

Nominal effective appreciation of the metical during recent months has reflected nominal bilateral stability with respect to the dollar. The nominal effective exchange rate for Mozambique is plotted versus nominal bilateral exchange rates in Figure 2. The principal destination for exports from Mozambique is the Euro Area, which accounted for 55 percent in 2007, while the principal source of imports is South Africa, which accounted for 37 percent. The metical appreciated by 22 percent in nominal terms against the euro during the year through February of 2009, and by 27 percent against the rand. Meanwhile, the metical appreciated by only 1 percent in nominal terms against the dollar. 
Figure 2. Nominal Effective Exchange Rate versus Nominal Bilateral Exchange Rates

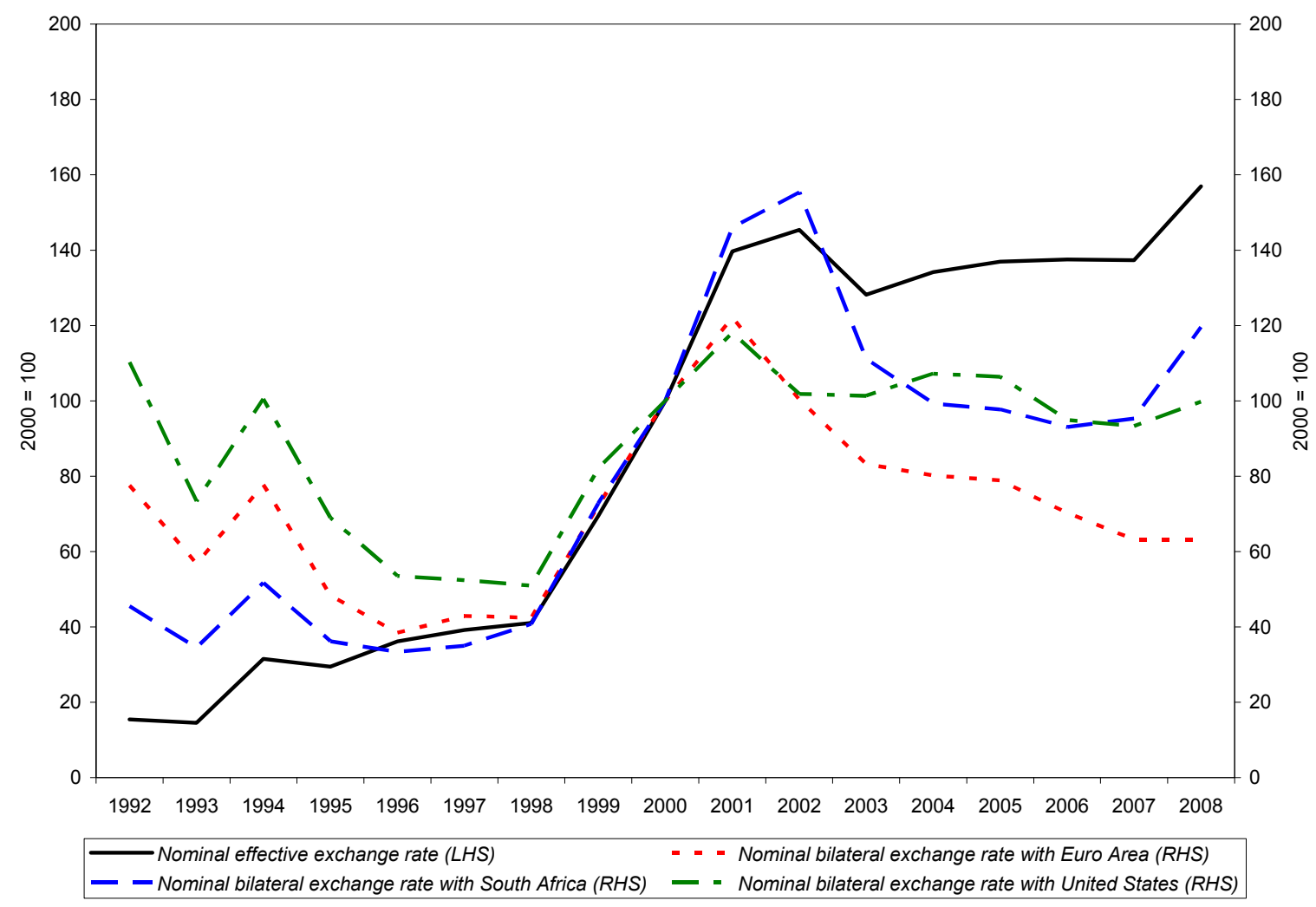

Real effective appreciation of the metical during recent months has been broadly based across major trading partners. The real effective exchange rate for Mozambique is plotted versus real bilateral exchange rates in Figure 3. The metical appreciated by 17 percent in real terms against the euro during the year through January of 2009, and by 37 percent against the rand. Meanwhile, the metical appreciated by only 6 percent in real terms against the dollar, reflecting nominal bilateral stability. In the absence of offsetting factors, this broadly based loss of external price competitiveness will raise the trade and current account deficits, draining official foreign exchange reserves. 
Figure 3. Real Effective Exchange Rate versus Real Bilateral Exchange Rates

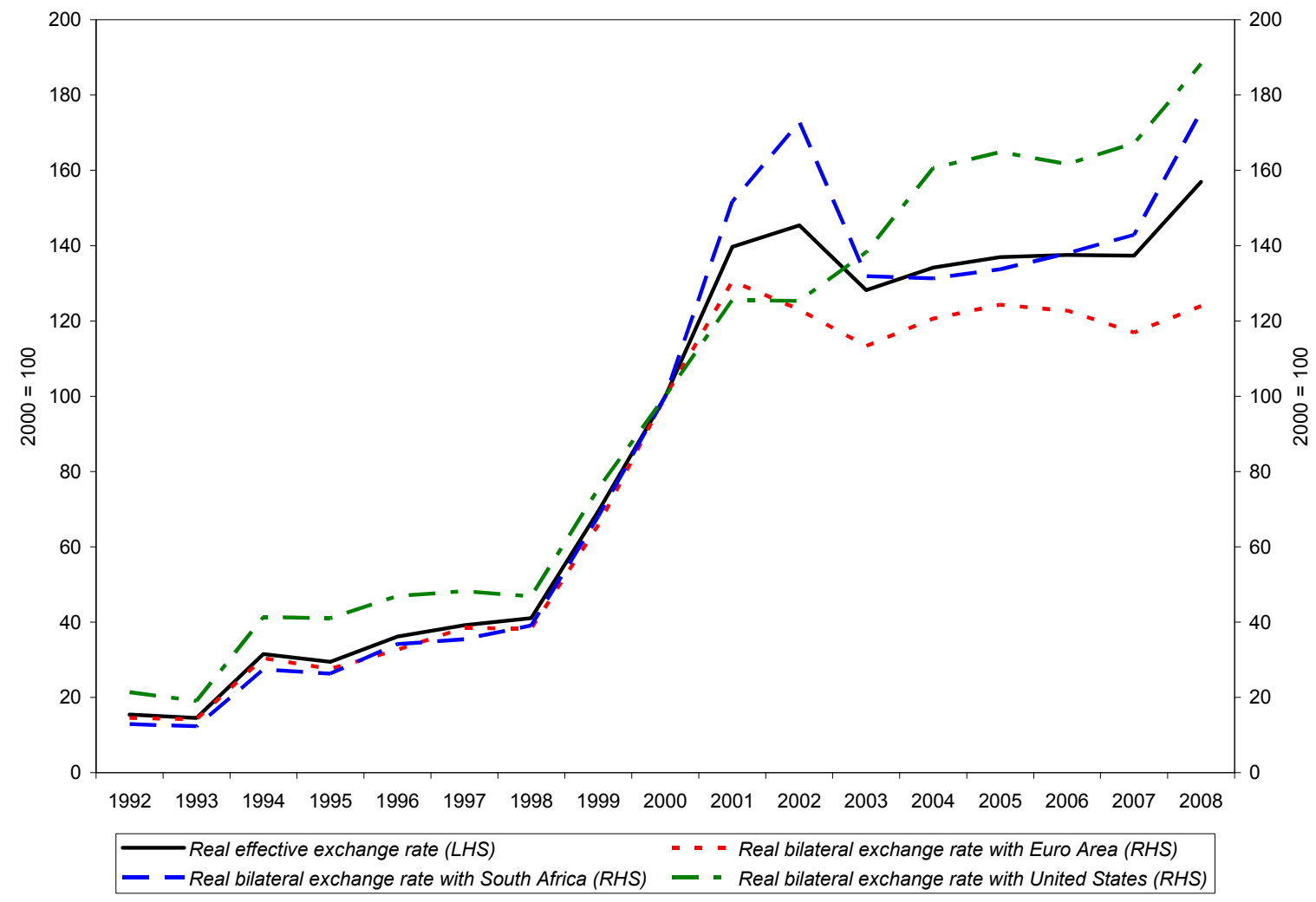

The real effective exchange rate of Mozambique is more sensitive to variation in its terms of trade for goods than its terms of trade for services, reflecting its status as a commodity exporter. The real effective exchange rate for Mozambique is plotted versus its terms of trade in Figure 4. The principal commodity exports of Mozambique are aluminum, bulk electricity, natural gas, tobacco, sugar, cotton, prawns, and cashews. Its principal commodity imports are machinery and equipment, vehicles, fuel, chemicals, metal products, foodstuffs, and textiles. 
Figure 4. Real Effective Exchange Rate versus Terms of Trade

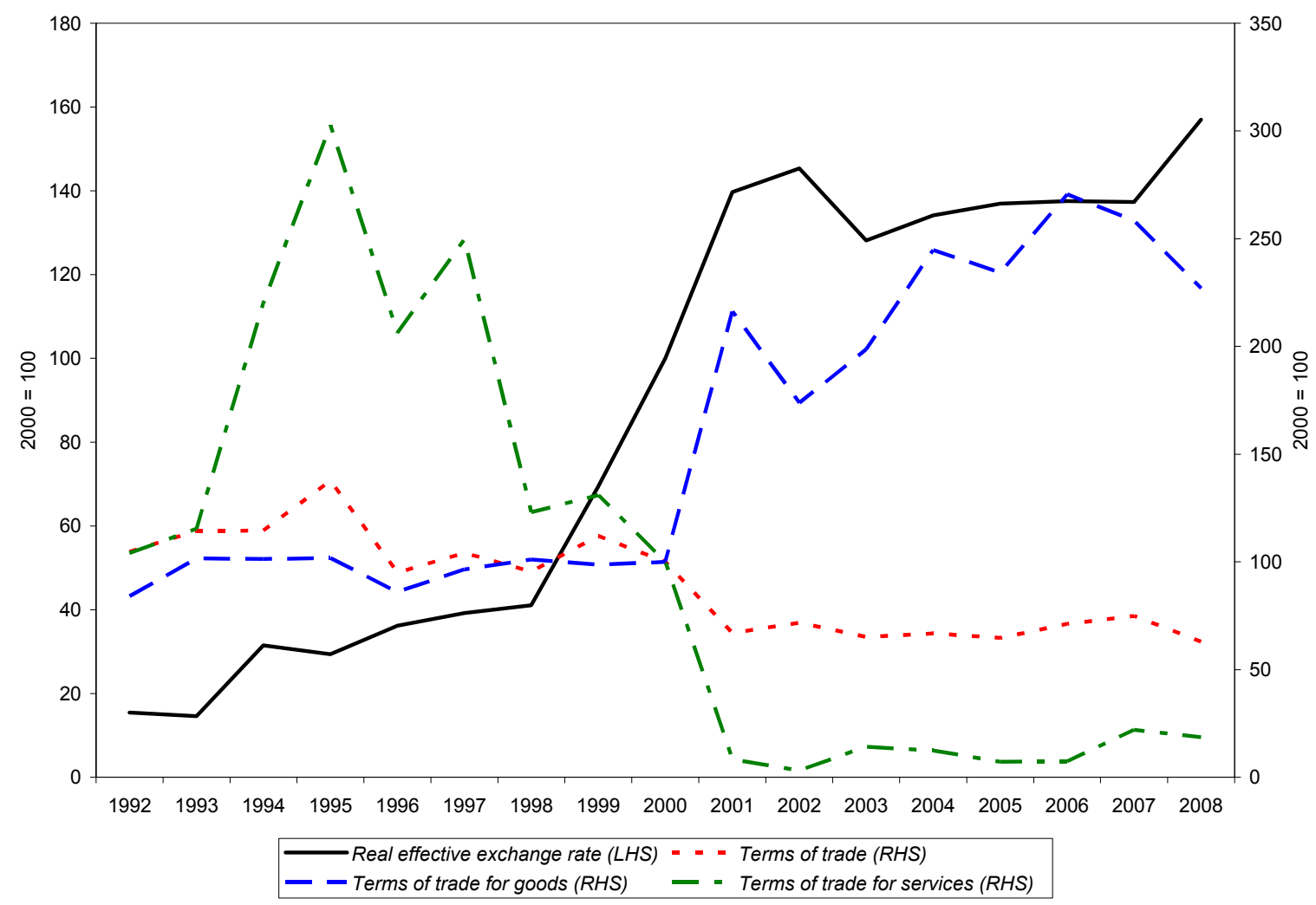

Cyclical variation in real effective exchange rates contributes to cyclical trade and current account imbalances. The real effective exchange rate for Mozambique is plotted versus its trade and current account balances in Figure 5. The trade deficit has tended to increase when the metical has appreciated in real effective terms, raising the current account deficit. This comovement between the trade deficit and the real effective exchange rate is strengthened by abstracting from aluminum, bulk electricity and natural gas megaprojects, which accounted for 76 percent of exports and 22 percent of imports in 2007. 
Figure 5. Real Effective Exchange Rate versus Trade and Current Account Balances

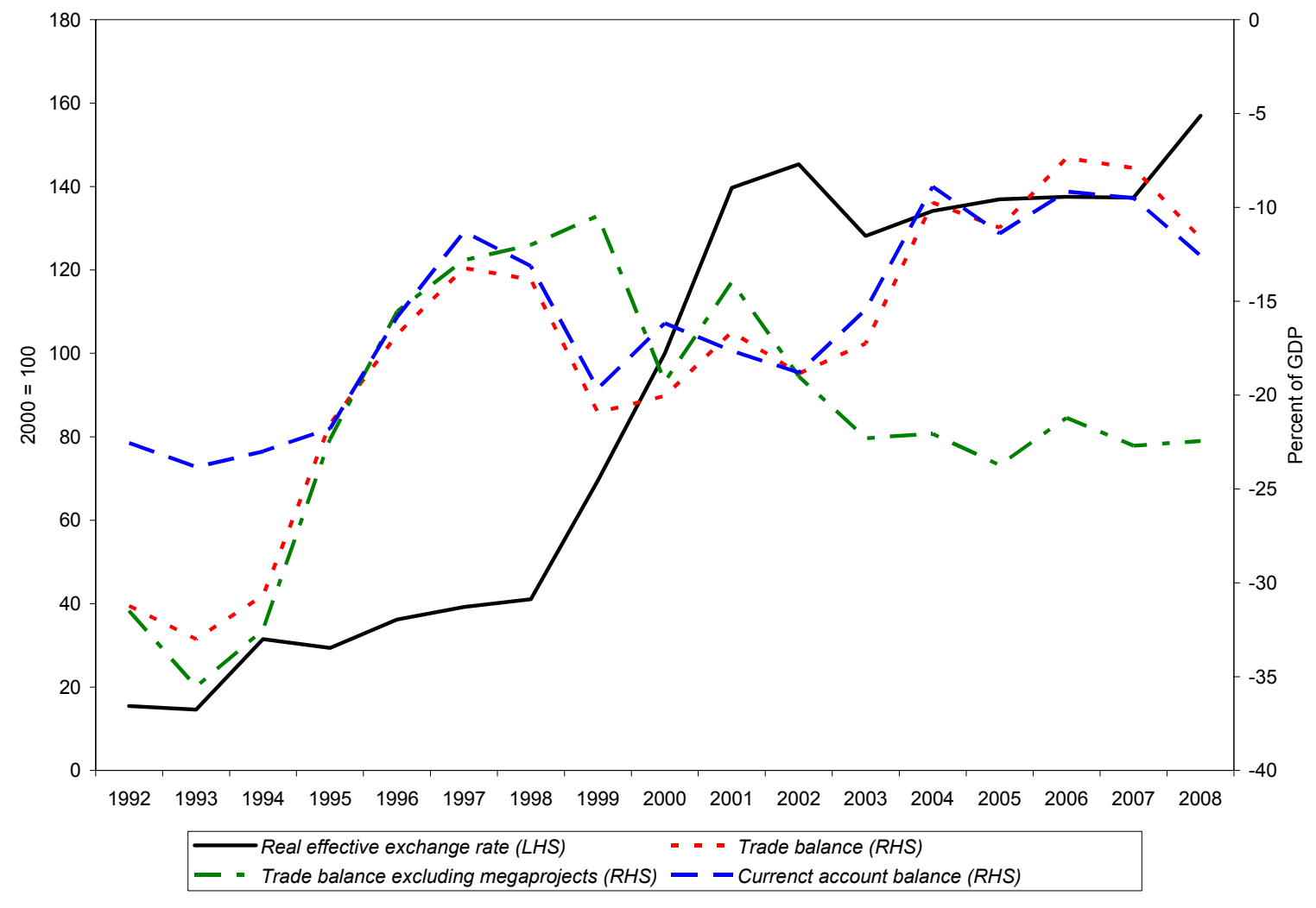

III. Exchange RATe AsSessment

As discussed in a recent survey paper by Isard (2007), there are a variety of alternative analytical approaches to conducting exchange rate assessments. Relative to a long run equilibrium concept, the most commonly applied analytical approach is purchasing power parity. Relative to a medium run equilibrium concept, the most commonly applied analytical approaches are the macroeconomic balance, equilibrium real exchange rate, and external sustainability approaches.

Under long run purchasing power parity, the logarithm of the real effective exchange rate is stationary, which implies that it reverts towards its unconditional mean. A variety of panel unit root tests decisively support this prediction. ${ }^{1}$ Under the purchasing power parity approach, the long run equilibrium value of the logarithm of the real effective exchange rate is estimated by its sample mean. The degree of long run exchange rate disequilibrium is then

\footnotetext{
${ }^{1}$ Both the panel unit root test developed by Levin, Lin and Chu (2002), which assumes common autoregressive parameters across time series, and the panel unit root test due to Im, Pesaran and Shin (2003), which allows for different autoregressive parameters across time series, reject the null hypothesis that the real effective exchange rate is nonstationary at conventional levels of statistical significance.
} 
inferred as the proportional difference between the most recently observed value of the real effective exchange rate and its estimated long run equilibrium value.

Application of the purchasing power parity approach to Mozambique indicates that the metical is overvalued by 256 percent in real effective terms. As illustrated by Figure 6, persistent appreciation of the metical in real effective terms has caused an enormous divergence of the real effective exchange rate from its estimated long run equilibrium value. An analysis of the extent to which this divergence reflects short run versus medium run factors is the subject of the remainder of this section.

Figure 6. Real Effective Exchange Rate versus Estimated Long Run Equilibrium Value

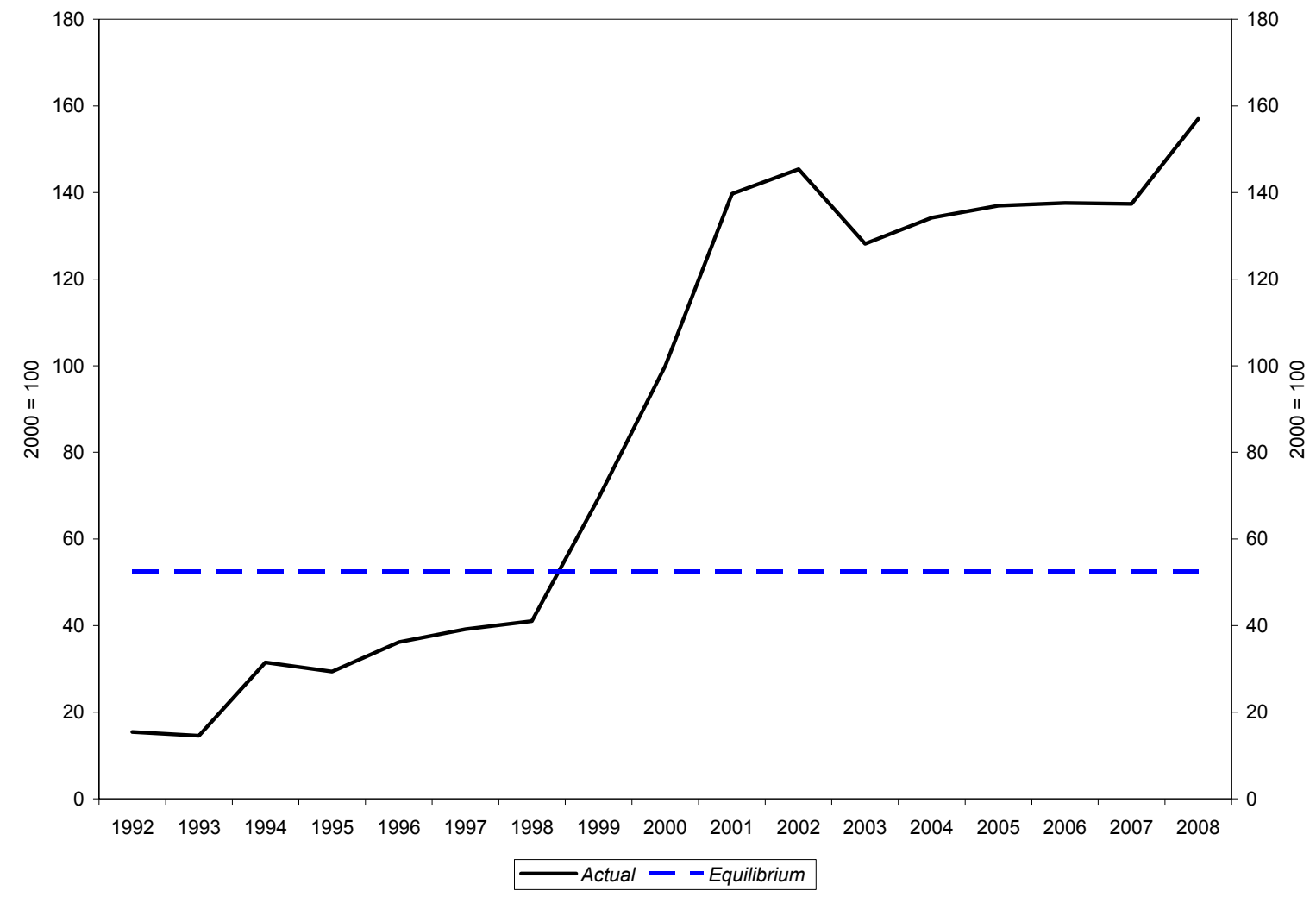

\section{A. The Macroeconomic Balance Approach}

Under the macroeconomic balance approach, the medium run equilibrium value of the ratio of the current account balance to output is jointly modeled from intertemporal and intratemporal perspectives. From the intertemporal perspective, the current account balance is modeled as a function of the determinants of saving and investment in medium run equilibrium, yielding a current account norm which is not a direct function of the real effective exchange rate. From the intratemporal perspective, the current account balance is modeled as a function of the determinants of exports and imports in medium run equilibrium, yielding an underlying current account balance which is a direct function of the real effective 
exchange rate. The degree of medium run exchange rate disequilibrium is then inferred as that proportional change in the real effective exchange rate needed to reconcile the underlying current account balance with the current account norm.

The empirical framework within which we model the current account norm is a panel regression model,

$$
c a_{i, t}=\beta_{0}+\boldsymbol{\beta}^{\top} \boldsymbol{x}_{i, t}+\varepsilon_{i, t},
$$

where $\varepsilon_{i, t} \sim \mathrm{N}\left(0, \sigma_{i}^{2}\right)$. As specified, $c a_{i, t}$ denotes the ratio of the current account balance to output for economy $i$ at time $t$, while $\boldsymbol{x}_{i, t}$ denotes a vector of explanatory variables. In addition to the explanatory variables considered by Lee et al (2008), we consider measures of aid and remittance inflows for emerging and developing economies. The current account norm is derived by evaluating this estimated panel regression model at medium run projections of its explanatory variables, while the underlying current account balance is equated to its medium run projection.

We estimate this panel regression model by the generalized method of moments while accounting for unconditional heteroskedasticity, given a data set spanning 182 economies over the period 1973 through 2008. For a detailed description of this panel data set, please refer to the Appendix. Lagged explanatory variables are employed as instruments to control for endogeneity, where necessary. Estimation results for unrestricted and restricted model specifications are reported in Table 2, where the restricted specification was determined with a general to specific model specification strategy. The restricted estimation results indicate that the current account balances of all economies are significantly influenced by most of the explanatory variables considered by Lee et al (2008) in medium run equilibrium. In addition, the current account balances of emerging and developing economies are significantly influenced by aid inflows in medium run equilibrium. 
Table 1. Estimation Results for the Macroeconomic Balance Approach

\begin{tabular}{llc}
\hline & Unrestricted & Restricted \\
\hline Relative old age dependency & $-0.173^{\star * *}$ & $-0.136^{\star * *}$ \\
Relative population growth & -0.344 & $\ldots$ \\
Relative income & $0.013^{\star * *}$ & $0.012^{* * *}$ \\
Relative income growth & $-0.639^{* * *}$ & $-0.513^{* * *}$ \\
Oil trade balance & $0.392^{* * *}$ & $0.346^{\star * *}$ \\
Relative fiscal balance & $0.186^{\star *}$ & $0.220^{* * *}$ \\
Initial net foreign assets & $0.049^{* * *}$ & $0.047^{\star * *}$ \\
Aid inflows & $0.171^{* *}$ & $0.141^{* *}$ \\
Remittance inflows & 0.037 & $\ldots$ \\
\hline Observations & 1,214 & 1,326 \\
R Squared & 0.396 & 0.390 \\
\hline
\end{tabular}

Note: One sided statistical significance at the 1 percent, 5 and 10 percent levels is indicated by ${ }^{* * *},{ }^{* *}$ and ${ }^{*}$, respectively.

Application of the macroeconomic balance approach to Mozambique indicates that the metical is overvalued by 26 percent in real effective terms. This overvaluation estimate is based on an estimated current account norm of -3.8 percent of output, as compared to an underlying current account balance estimate of -7.8 percent of output. As illustrated by Figure 7, relatively low old age dependency and high aid inflows are important positive contributors to the estimated current account norm. In opposition, relatively low income, relatively high income growth, a high oil trade deficit, and a high net foreign debt are important negative contributors. 
Figure 7. Current Account Balance versus Estimated Medium Run Equilibrium Value

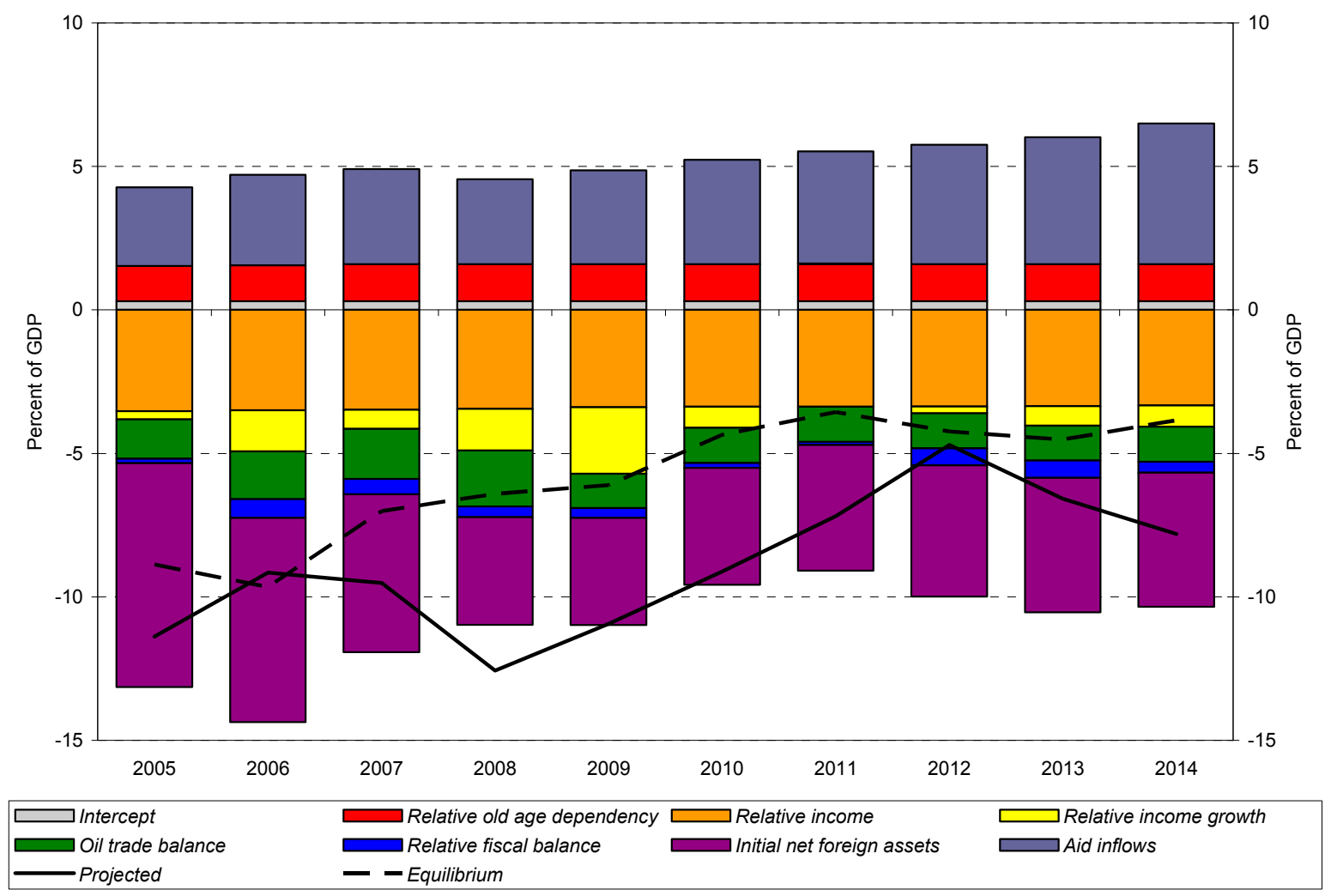

B. The Equilibrium Real Exchange Rate Approach

Under the equilibrium real exchange rate approach, the medium run equilibrium value of the real effective exchange rate is modeled as a function of factors which cause temporary but persistent deviations from long run purchasing power parity. The degree of medium run exchange rate disequilibrium is then inferred as the proportional difference between the most recently observed value of the real effective exchange rate and its estimated medium run equilibrium value.

The empirical framework within which we model the medium run equilibrium value of the real effective exchange rate is a panel regression model,

$$
\ln Q_{i, t}=\beta_{0, i}+\boldsymbol{\beta}^{\top} \boldsymbol{x}_{i, t}+\varepsilon_{i, t},
$$

where $\beta_{0, i}$ denotes an economy specific fixed effect, and $\varepsilon_{i, t} \sim \mathrm{N}\left(0, \sigma_{i}^{2}\right)$. As specified, $Q_{i, t}$ denotes the real effective exchange rate for economy $i$ at time $t$, while $\boldsymbol{x}_{i, t}$ denotes a vector of explanatory variables. In addition to the explanatory variables considered by Lee et al (2008), we consider measures of aid and remittance inflows for emerging and developing economies. The medium run equilibrium value of the real effective exchange rate is derived 
by evaluating this estimated panel regression model at medium run projections of its explanatory variables.

We estimate this panel regression model by the generalized method of moments while accounting for unconditional heteroskedasticity, given a data set spanning 182 economies over the period 1973 through 2008. Lagged explanatory variables are employed as instruments to control for endogeneity. Estimation results for unrestricted and restricted model specifications are reported in Table 2. The restricted estimation results indicate that real effective exchange rate dynamics are primarily driven by variation in the terms of trade for goods, relative productivity, and relative government consumption in medium run equilibrium.

Table 2. Estimation Results for the Equilibrium Real Exchange Rate Approach

\begin{tabular}{lcc}
\hline & Unrestricted & Restricted \\
\hline Terms of trade for goods & $0.242^{* * *}$ & $0.146^{* * *}$ \\
Terms of trade for services & $0.209^{* * *}$ & $\ldots$ \\
Relative productivity & $0.292^{* *}$ & $0.392^{* * *}$ \\
Relative government consumption & 0.718 & $1.524^{* * *}$ \\
Net foreign assets & -0.194 & $\ldots$ \\
Aid inflows & -12.247 & $\ldots$ \\
Remittance inflows & -1.177 & $\ldots$ \\
\hline Observations & 818 & 1,607 \\
R Squared & 0.567 & 0.526 \\
\hline
\end{tabular}

Note: One sided statistical significance at the 1 percent, 5 percent and 10 percent levels is indicated by ${ }^{* * *}$, ${ }^{* *}$, and *.

Application of the equilibrium real exchange rate approach to Mozambique indicates that the metical is overvalued by 41 percent in real effective terms. As illustrated by Figure 8, a high terms of trade for goods is an important positive contributor to the estimated medium run equilibrium real effective exchange rate, while relatively low government consumption is an important negative contributor. The contribution of relative productivity is restricted to equal zero as this explanatory variable is not observed. 
Figure 8. Real Effective Exchange Rate versus Estimated Medium Run Equilibrium Value

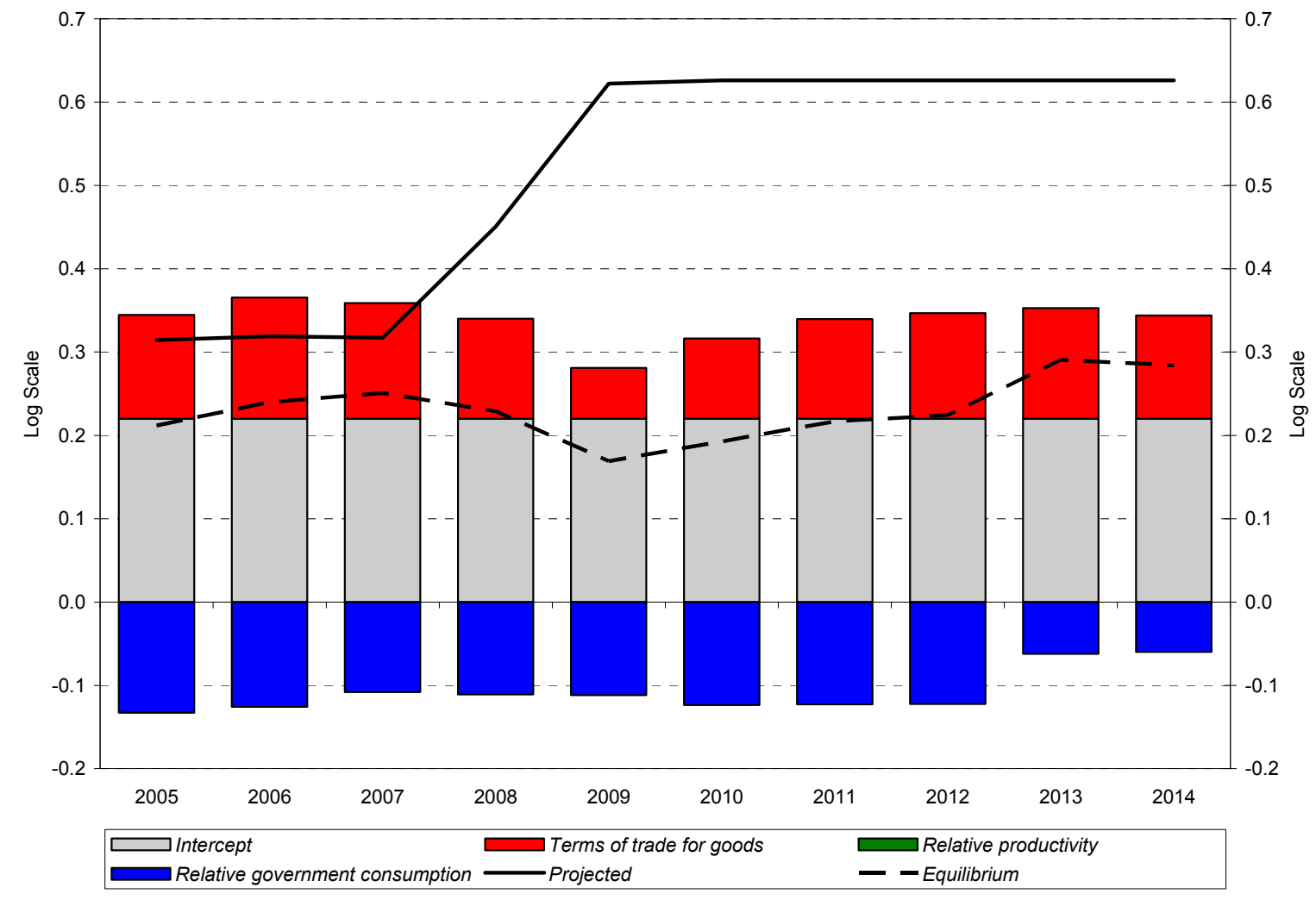

\section{The External Sustainability Approach}

Under the external sustainability approach, the current account norm is equated to that ratio of the current account balance to output needed to stabilize the ratio of the net foreign asset position to output around its estimated medium run equilibrium value. ${ }^{2}$ Following the macroeconomic balance approach, the degree of medium run exchange rate disequilibrium is then inferred as that proportional change in the real effective exchange rate needed to reconcile the underlying current account balance with this current account norm. The empirical framework within which we model the net foreign asset position norm is a panel regression model,

$$
n f a_{i, t}=\beta_{0, i}+\boldsymbol{\beta}^{\top} \boldsymbol{x}_{i, t}+\varepsilon_{i, t},
$$

\footnotetext{
${ }^{2}$ Let the current account balance $C A_{i, t}$ equal the change in the net foreign asset position $N F A_{i, t}$, that is $C A_{i, t}=N F A_{i, t}-N F A_{i, t-1}$. Imposing steady state equilibrium conditions on this balance of payments identity yields $c a_{i}=\frac{g_{i}}{1+g} n f a_{i}$, where $c a_{i}$ denotes the steady state equilibrium ratio of the current account balance to output, $n f a_{i}$ denotes the steady state equilibrium ratio of the net foreign asset position to output, and $g_{i}$ denotes the steady state equilibrium growth rate of nominal output.
} 
where $\beta_{0, i}$ denotes an economy specific fixed effect, and $\varepsilon_{i, t} \sim \mathrm{N}\left(0, \sigma_{i}^{2}\right)$. As specified, $n f a_{i, t}$ denotes the ratio of the net foreign asset position to output for economy $i$ at time $t$, while $\boldsymbol{x}_{i, t}$ denotes a vector of explanatory variables. The net foreign asset position norm is derived by evaluating this estimated panel regression model conditional on medium run projections of its explanatory variables.

We estimate this panel regression model by the generalized method of moments while accounting for unconditional heteroskedasticity, given a data set spanning 182 economies over the period 1973 through 2008. For a detailed description of this panel data set, please refer to the Appendix. Lagged explanatory variables are employed as instruments to control for endogeneity, where necessary. Estimation results for unrestricted and restricted model specifications are reported in Table 2, where the restricted specification was determined with a general to specific model specification strategy. The restricted estimation results indicate that accumulated net foreign asset positions are significantly influenced by relative old age dependency and government net debt in medium run equilibrium.

Table 3. Estimation Results for the External Sustainability Approach

\begin{tabular}{lcc}
\hline & Unrestricted & Restricted \\
\hline Relative old age dependency & $1.387^{* * *}$ & $1.376^{* * *}$ \\
Relative income & -0.630 & $\ldots$ \\
Government net debt & $-0.341^{* * *}$ & $-0.247^{* * *}$ \\
\hline Observations & 995 & 1,012 \\
R Squared & 0.861 & 0.849 \\
\hline
\end{tabular}

Note: One sided statistical significance at the 1 percent, 5 percent, and 10 percent levels is indicated by ${ }^{* * *},{ }^{* *}$, and ${ }^{*}$.

Application of the external sustainability approach to Mozambique indicates that the metical is overvalued by 38 percent in real effective terms. This overvaluation estimate is based on an estimated net foreign asset position norm of -18.4 percent of output. This implies an estimated current account norm of -1.9 percent of output, as compared to an underlying current account balance estimate of -7.8 percent of output. As illustrated by Figure 9, relatively low old age dependency is an important negative contributor to the estimated current account norm. The contribution of government net debt is restricted to equal zero as this explanatory variable is not observed. 
Figure 9. Net Foreign Asset Position versus Estimated Medium Run Equilibrium Value

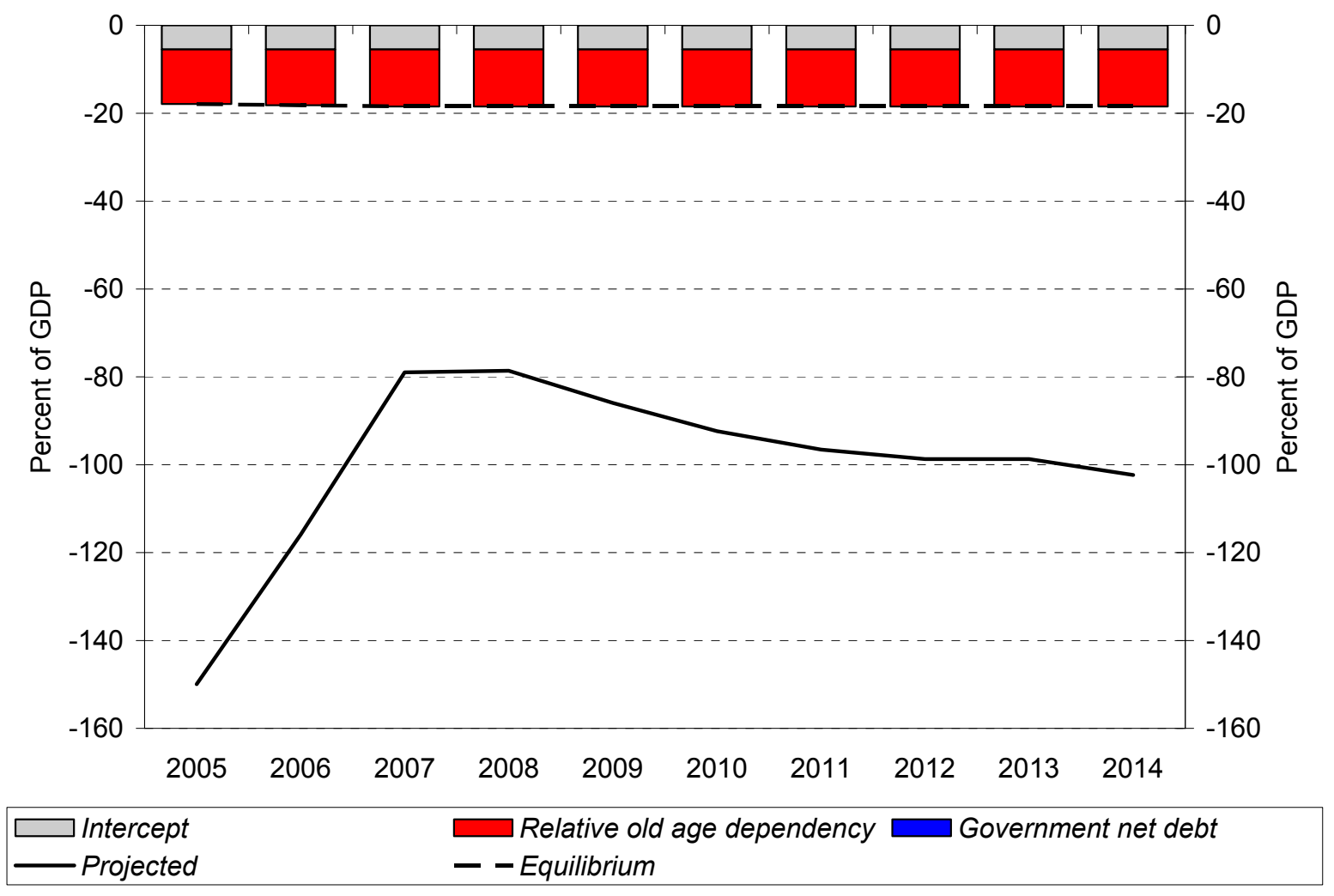

D. Summary of Exchange Rate Assessment Results

A variety of indicators suggest that Mozambique has recently lost external price competitiveness with respect to its major trading partners. Consistent with these indicators, an exchange rate assessment based on the macroeconomic balance, equilibrium real exchange rate, and external sustainability approaches indicates that the metical is overvalued by 26 to 41 percent in real effective terms. 
Table 4. Summary of Exchange Rate Assessment Results

\begin{tabular}{lcccc} 
& \multirow{2}{*}{ NFA/GDP } & \multicolumn{2}{c}{ CAB/GDP } & REER \\
\cline { 3 - 4 } & & Norm & Underlying & \\
\hline MB & $\ldots$ & -3.8 & -7.8 & 25.6 \\
ERER & $\ldots$ & $\ldots$ & $\ldots$ & 40.8 \\
ES & -18.4 & -1.9 & -7.8 & 38.4 \\
\hline $\begin{array}{l}\text { Note: Overvaluation estimates are based on a medium run semi-elasticity of the ratio of the current account balance to } \\
\text { output with respect to the real effective exchange rate of }-0.155, \text { and a medium run equilibrium nominal output growth } \\
\text { rate of } 11.2 \text { percent. All estimates are based on five year projections, and are expressed in percent. }\end{array}$ \\
\hline
\end{tabular}

\section{Policy Recommendations}

Substantial currency overvaluation in Mozambique has the potential to significantly impede its economic development. Supporting economic growth and safeguarding external stability calls for an adjustment of monetary policy to gradually restore external price competitiveness.

In the short run, a loss of external price competitiveness in Mozambique, caused in part by accommodating real effective appreciation pressure generated by aid inflows, will decrease output relative to its potential by reducing export demand and raising import demand. In the absence of offsetting factors, this will raise the trade and current account deficits, draining official foreign exchange reserves and jeopardizing external stability. If sustained over the medium run, this loss of external price competitiveness may also reduce potential output by diverting resources from established or prospective comparative advantage industries as foreign direct investment declines along with the expected profitability of potential investment projects. Paradoxically, high aid inflows can ultimately lower living standards if appreciation of the currency in real effective terms stifles economic development, fostering continued aid dependence. Meanwhile, concentration of the export base among megaprojects which retain comparative advantage risks exacerbating external instability and amplifying the volatility of the business cycle by elevating the exposure of the economy to particular commodity price shocks.

Restoring external price competitiveness in Mozambique through an adjustment of monetary policy can safeguard against falling into this development trap. Since the process of restoring external price competitiveness through depreciation of the currency in nominal effective terms is inflationary, a gradual process of adjustment is desirable. Moreover, the rate of adjustment should vary with the degree of inflationary pressure, with low projected inflation offering an opportunity to restore external price competitiveness at a faster rate. The ongoing global economic crisis, which has reduced imported inflationary pressure, offers such an opportunity. 


\section{Appendix}

The panel data set consists of annual observations on several macroeconomic variables for 182 economies over the period 1973 through 2008, together with projections of these variables over the period 2009 through 2014. This panel data set is unbalanced, in the sense that the number of observations varies across variables along both the cross sectional and time series dimensions. The set of economies under consideration spans all advanced, emerging, and developing economies contained in the World Economic Outlook database maintained by the International Monetary Fund. The time period under consideration begins after the collapse of the Bretton Woods system of fixed exchange rates.

Under the macroeconomic balance approach, the dependent variable is the ratio of the current account balance to output, while the explanatory variables considered are: the ratio of the retirement age population to the working age population, expressed as a deviation from a trade weighted average across trading partners; the growth rate of the population, expressed as a deviation from a trade weighted average across trading partners; the logarithm of income per capita expressed in terms of purchasing power, expressed as a deviation from a trade weighted average across trading partners; the growth rate of income per capita expressed in terms of purchasing power, expressed as a deviation from a trade weighted average across trading partners; the ratio of the oil trade balance to output; the ratio of the fiscal balance to output, expressed as a deviation from a trade weighted average across trading partners; the lagged ratio of the net foreign asset position to output; the ratio of official aid receipts to output; and the ratio of remittance receipts to output.

Under the equilibrium real exchange rate approach, the dependent variable is the logarithm of the real effective exchange rate, based on the consumer price index. The explanatory variables considered are: the logarithm of the terms of trade for goods; the logarithm of the terms of trade for services; the logarithm of output per worker expressed in terms of purchasing power, expressed as a deviation from a trade weighted average across trading partners; the ratio of government consumption to output, expressed as a deviation from a trade weighted average across trading partners; the ratio of the net foreign asset position to output; the ratio of official aid receipts to output; and the ratio of remittance receipts to output.

Under the external sustainability approach, the dependent variable is the ratio of the net foreign asset position to output, while the explanatory variables considered are: the ratio of the retirement age population to the working age population, expressed as a deviation from a trade weighted average across trading partners; the logarithm of income per capita expressed in terms of purchasing power, expressed as a deviation from a trade weighted average across trading partners; and the ratio of the government net debt to output.

Where possible, data and projections for Mozambique were obtained from the macroeconomic framework associated with the 2009 Article IV Consultation with the 
International Monetary Fund, while data and projections for other economies were retrieved from the April 2009 vintage of the World Economic Outlook database maintained by the International Monetary Fund. Where necessary, data was retrieved from other databases maintained by the International Monetary Fund or the World Bank Group, and projections were generated. In particular, effective exchange rate data was obtained from the Information Notice System database, net foreign asset position data was retrieved from the International Investment Position database, and other data was extracted from the World Development Indicators database. 


\section{References}

Im, K., M. Pesaran, and Y. Shin, 2003, "Testing for Unit Roots in Heterogeneous Panels," Journal of Econometrics, Vol. 115, pp. 53-74.

Isard, P., 2007, “Equilibrium Exchange Rates: Assessment Methodologies,” IMF Working Paper No. 296 (Washington: International Monetary Fund).

Lee, J., G. Milesi-Ferretti, J. Ostry, A. Prati, and L. Ricci, 2008, "Exchange Rate Assessments: CGER Methodologies,” IMF Occasional Paper No. 261 (Washington: International Monetary Fund).

Levin, A., C. Lin, and C. Chu, 2002, "Unit Root Tests in Panel Data: Asymptotic and FiniteSample Properties," Journal of Econometrics, Vol. 108, pp. 1-24. 